Diversa 


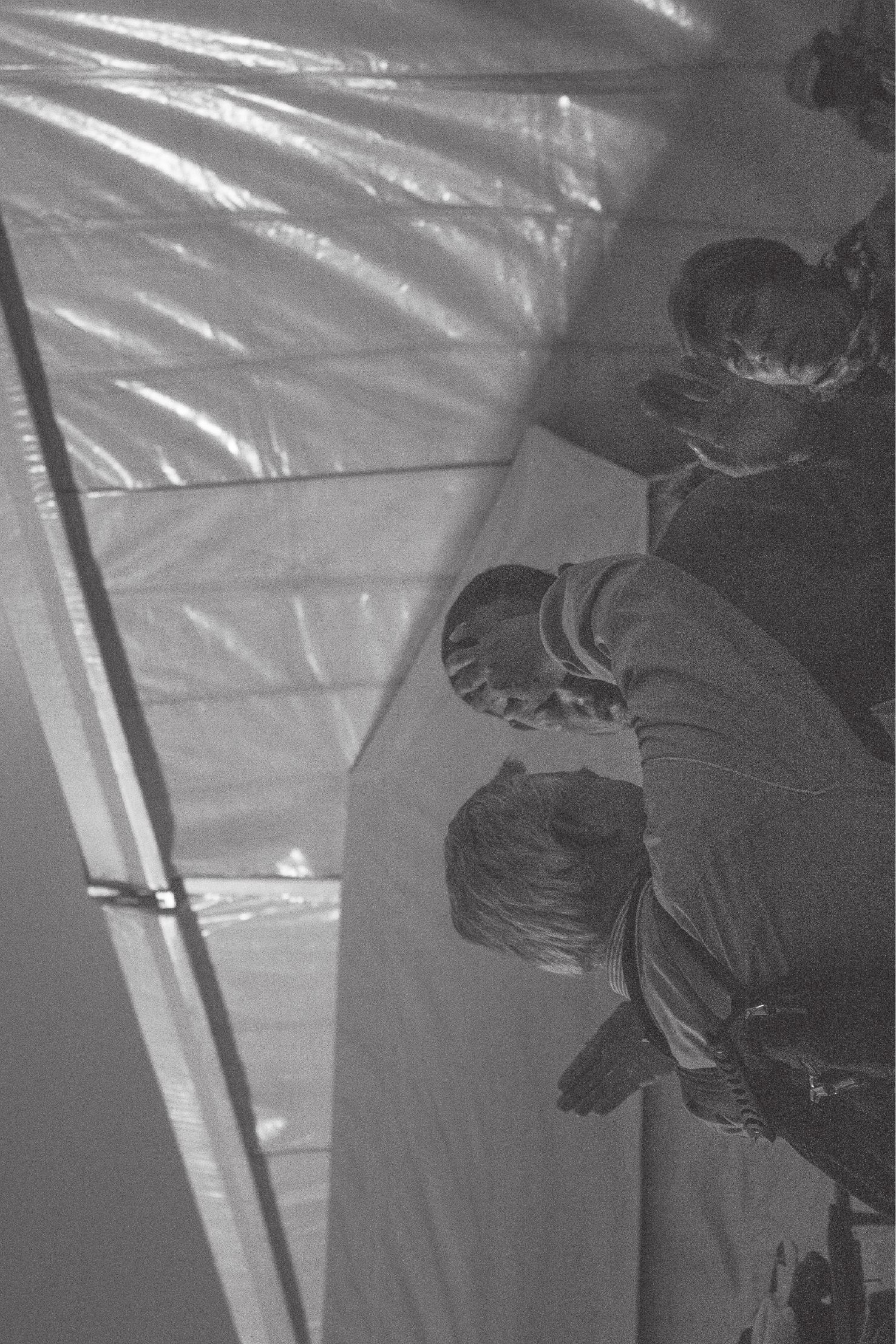




\title{
La traducción como acto doble de comunicación. Entre semiótica cognoscitiva y semiótica
} de la cultura. ${ }^{1}$ Parte II:* De la traducción a la transposición

\author{
Translation as a Double Act of Communication. \\ Between Semiotic and Cognitive Semiotics \\ of Culture. Part II: From Translation to Transposition
}

\author{
Göran Sonesson \\ Centro de Semiótica Cognoscitiva \\ Universidad de Lund \\ goran.sonesson@semiotik.lu.se
}

\begin{abstract}
Resumen: En la primera parte de este trabajo concluimos que la traducción es un doble acto de significación, tomando en cuenta los casos de emisión y recepción de ambos actos involucrados, el primero en el nivel de la cognición, y el segundo en el nivel de la comunicación. Dada esta definición, se muestra que la "traducción intralingüística" de Jakobson es, en cierto sentido, lo contrario de la traducción, mientras que su "traducción intersemiótica" tiene similitudes, así como importantes diferencias con respecto a la traducción en el sentido literal. Para clarificar las diferencias, tenemos que profundizar en las distintas maneras en que el lenguaje y las imágenes presentan la significación. También veremos que la "traducción cultural", en el sentido de la Escuela de Tartú, tiene muy poco que ver con la traducción en el sentido propio, excepto, en algunos casos, en la última fase de su funcionamiento. La idea de Peirce de cambiar signos por otros signos se entiende mejor como una caracterización de la tradición.
\end{abstract}

Palabras clave: traducción, comunicación, cognición, semiótica cultural, recursos semióticos

1 La primera versión de este texto se presentó en el congreso de la IASS-AIS en Nanjing en 2012 (véase ahora Sonesson 2014). Desde entonces, he tenido la oportunidad de ofrecer esta conferencia en Salónica, Helsinki, Lublin, Lund y en la Ciudad de México, y estas experiencias han inspirado cambios fundamentales al modelo propuesto en Nanjing. Quiero agradecer a los que asistieron a estas conferencias sus comentarios, que han dado lugar a varias revisiones y aclaraciones.

* La parte I de este artículo se publicó en el número anterior de Interpretatio. 
Abstract: In the first part of this work we concluded that translation is a double act of signification, taking into account the instances of emission and reception of both acts involved, the first at the level of cognition, and the second at the level of communication. Given this definition, it is shown that the "intralinguistic translation" of Jakobson is, in a certain sense, the opposite of translation, while his "intersemiotic translation" manifests similarities as well as important differences with respect to translation in the literal sense. To clarify the differences, we must delve into the different ways in which language and pictures present meaning. We will also see that the "cultural translation", in the sense of the Tartu School, has very little to do with translation in the proper sense, except, in some cases, in the last phase of its operation. Peirce's idea of exchanging signs for other signs is better understood as a characterization of tradition.

Keywords: translation, communication, cognition, semiotic, cultural, semiotic resources

Recibido: $\quad 5$ de febrero de 2018

Aceptado: 19 de julio de 2018

En la primera parte de este artículo establecimos que la traducción debe ser considerada como un doble acto de comunicación, y no confundirla con dos actos consecutivos de comunicación. En este sentido, para que exista un doble acto de comunicación, no solo hacen falta dos actos de comunicación, uno seguido del otro, sino el contenido de los dos debiera ser, en el sentido calificado del término, idéntico a lo largo de los actos, lo cual es imposible por diferentes razones, como vamos a ver en los casos que Jakobson llama la transposición intralingüística y la transposición intersemiótica. Por lo tanto, no es la secuencia de dos actos de comunicación del cual el segundo es una traducción del primero, lo que hace de la traducción un doble acto de comunicación, sino el hecho de que este segundo acto debe tomar en cuenta la situación del emisor y del receptor del acto original, así como del que tiene lugar actualmente.

\section{De la traducción a la transposición}

En el sentido pleno de la hermenéutica se conoce como tradición a la serie de situaciones de comunicación conectadas entre sí que permite cambios de significado en función de la adaptación a la fuente o al destino. Dada una dimensión de tiempo menos extensa, también podría ser descrita como la pro- 
pagación de un rumor. En ambos casos ocurre un cambio de contenido con cada paso de un actor a otro. En este nivel, es fácil reconocer en la traducción algo que se parece a la serie infinita peirceana de interpretantes dando paso siempre a nuevos interpretantes. Sin embargo, normalmente una tradición o un rumor no requieren ningún cambio de idioma. Nos mantenemos dentro de la esfera de la misma lengua y la misma cultura. De hecho, una tradición solo puede con dificultad, o tal vez no del todo, ser traducida de un idioma a otro y de una cultura a otra. La traducción, sin embargo, es una tradición que tiene como objetivo conservar el mismo contenido tanto como sea posible a través de diferentes actos de comunicación.

\subsection{Los tres tipos de traducción de Jakobson}

De acuerdo con un texto famoso de Roman Jakobson (1959), como ya se mencionó, la traducción no solo tiene lugar de un idioma (verbal) a otro. También puede involucrar una sola lengua; $y$, asimismo, puede relacionar diferentes recursos semióticos. La traducción como normalmente se entiende se vuelve entonces traducción interlingüística, también reconocida por Jakobson como "traducción propiamente dicha". La traducción intralingüística es cuando cambiamos una palabra o frase del mismo idioma por otra posible. La traducción intersemiótica, por último, implica la transferencia de un contenido de un tipo de medio semiótico a otro, por ejemplo, cuando se ilustra un cuento con una imagen o cuando se hace una película de una novela. Si aceptamos estos términos, las traducciones intralingüísticas e interlingüísticas son, ambas, traducciones intrasemióticas (internas a un recurso semiótico).

La traducción de un texto verbal acompañado de una imagen implica todos estos tipos de comparaciones, y tal vez varios más. Si el texto verbal está determinado por el "texto" pictórico y/o lo determina, entonces el traductor puede sentir la necesidad de tener acceso a este último, a fin de traducir el primero (cf. Sonesson 1996). En la mayoría de los casos, la transposición lingüística implica, al mismo tiempo, una transposición cultural. Por lo general, el problema planteado por la imagen, desde el punto de vista del traductor, es cultural, más que intrínseco al medio pictórico, es decir, se refiere a la forma en que el mundo perceptual y/o sociocultural se representa en la imagen. Es posible, sin duda, imaginar casos en los que está involucrado el mismo tipo de imagen: así, imágenes altamente codificadas, como el icono ruso o una 
pintura cubista, pueden necesitar ser traducidas a otro estilo pictórico antes de poder funcionar en otras culturas. Pero estos son sin duda casos excepcionales.

$\mathrm{Al}$ igual que en el caso de las imágenes anormales, las imágenes que tienen contenido con carga cultural pueden ser canjeadas por otras o simplemente ser modificadas. Esto implica el trabajo de un profesional diferente a lo que se conoce normalmente como traductor. Por otra parte, el traductor puede tratar de compensar la desviación cultural de la imagen mediante la adición de elementos que no se encuentran en la parte verbal del texto de origen. En este punto, la cuestión de si los sistemas de signos verbales y pictóricos se organizan de manera similar, y por lo tanto son capaces de empaquetar el mismo tipo de información, se vuelve relevante.

La traducción de una cultura a otra sigue siendo, en términos de Jakobson, una traducción intersemiótica. Sin embargo, ya que implica la transposición, no solo de un sistema semiótico, sino de elementos provenientes de toda la cultura, tal vez sea mejor recurrir a los términos de la semiótica de la cultura iniciados por la Escuela de Tartú, según la cual esta representa un caso de traducción cultural -o tal vez mejor, intercultural-. Típicamente, la traducción intercultural da lugar a deformaciones que solo serán remediadas cuando la familiaridad con los textos extranjeros haya hecho posible que la cultura receptora establezca su propia versión del sistema de producción cultural que antes generaron los textos. Esta es otra razón para sostener que la traducción cultural no es una traducción en el sentido estricto.

\subsection{La traducción y la transposición intralingüística}

La traducción —en todos los sentidos de Jakobson, excepto tal vez la intralingüística - requiere un intermediario versado en ambos medios y/o culturas. Sin embargo, hay razones para pensar que aparte de la "traducción propiamente dicha”, como la llama Jakobson, las otras categorías son solo traducciones en una manera bastante metafórica. Con el fin de mantener la discusión más ordenada, en lo que sigue voy a hablar de tres (o cuatro) tipos de transposición, de los cuales solo uno es conocido como traducción. ${ }^{2}$

2 Un término como transposición no evita en realidad la metáfora del tubo, pero sugiere, al menos, un pasaje a otro nivel. Es lo mejor que podemos hacer, en cualquier caso, dados los términos de los cuales disponemos. 
En el caso de la transposición intralingüística, ningún acto doble parece ser necesario, por lo menos ninguno que involucre a un participante adicional. Al principio, puede parecer todo lo contrario a una traducción: mientras que en la traducción se busca una expresión nueva tratando de mantener el contenido lo más estable posible, en este caso se sustituye un nuevo signo por el anterior, cuyo contenido se mantiene constante en parte, pero cuya expresión puede ser completamente diferente, con el propósito de ser más fiel al referente. En este caso, la instancia de la regularidad es la referencia: teniendo en cuenta la naturaleza del referente se busca el término apropiado.

Sin embargo, si suponemos que la sustitución de las palabras se hace en beneficio de un público particular, como los niños o los extranjeros con un dominio limitado del idioma involucrado, la transposición intralingüística se vuelve más similar a la traducción. Aquí la instancia normativa, como en la traducción, es el público. Se intenta transmitir el mismo sentido, en la medida en que esto sea posible, a un receptor que dispone de un fondo de conocimientos diferente y/o más limitado. Sin embargo, esto no es un doble acto de comunicación. No hay un público doble. Incluso si suponemos que el sujeto "traduce" lo que primero quería decir, no tiene que dar cuenta de las condiciones de cualquier acto anterior - y esto es una diferencia con la traducción verdadera- - Sin embargo, al ampliar la perspectiva de las palabras al discurso, la "traducción" intralingüística resulta muy dependiente del entorno extralingüístico o extrasígnico (Cuadro 1, sacado de Sonesson 1989, inspirado en la obra de Luis Prieto 1966). En cierto modo, lo que no está presente como un objeto real en la situación de percepción tiene que ser "traducido" (o transpuesto) al lenguaje, mientras que los objetos percibidos pueden, al menos en parte, quedar fuera de la "traducción". Las diferencias de medio ambiente también pueden hacer la diferencia para la "traducción propiamente dicha”, en primer lugar, porque el ambiente extralingüístico y/o extrasígnico puede ser diferente y, en segundo lugar, porque las reglas de redundancia pueden ser diferentes. ${ }^{3}$

3 La interpretación de los signos en forma de otros signos según Peirce puede ser un caso de transposición intrasemiótica. Podría también, por supuesto, ser una transposición intersemiótica. Incluso podría tratarse de un diálogo entre diferentes sujetos. En cualquier caso, no requiere un doble acto. 


\begin{tabular}{|c|c|c|c|c|c|c|c|c|c|}
\hline & $\begin{array}{l}\text { “Give” Imp } \\
\text { 3III P1 IDO } \\
\text { Ip Sg }\end{array}$ & Poss & Ip & $\mathrm{Sg}$ & ofDO & $\mathrm{DO}$ & $\mathrm{Sg}$ & $\mathrm{M} / \mathrm{F}$ & "Book" \\
\hline $\begin{array}{l}\text { Donnez-moi } \\
\text { mon livre! }\end{array}$ & + & + & + & + & + & + & + & + & + \\
\hline $\begin{array}{l}\text { Donnez-moi le } \\
\text { mien! }\end{array}$ & + & + & + & + & + & + & + & + & - \\
\hline $\begin{array}{l}\text { Donnez-moi le } \\
\text { livre! }\end{array}$ & + & - & - & - & - & + & + & + & + \\
\hline Donnez-le-moi! & + & - & - & - & - & + & + & + & - \\
\hline Donnez-moi! & + & - & - & - & - & - & - & - & - \\
\hline \multirow{3}{*}{$\begin{array}{l}\text { Combinaciones } \\
\text { imposibles }\end{array}$} & + & + & + & + & + & - & - & - & - \\
\hline & + & + & - & + & + & \pm & \pm & \pm & \pm \\
\hline & + & + & + & - & + & \pm & \pm & \pm & \pm \\
\hline
\end{tabular}

CUADRO 1. La "traducción intralingüística" adaptada al contexto y los presupuestos, tal como fue concebida por Prieto 1966 e ilustrada en Sonesson 1989.

\subsection{Traducción y transposición intersemiótica}

Mientras que la distancia entre los signos sustituidos en la transposición intralingüística puede parecer demasiado corta para ser considerada una traducción, en el caso de la transposición intersemiótica el camino de una expresión a un contenido diferente puede parecer demasiado largo para ese propósito. Por ejemplo, para pasar de una descripción lingüística a una imagen, se tendría que recuperar una gran cantidad de información que no se tiene posibilidad de conocer, por no haber estado presente en el primer acto de comunicación, sin importar lo mucho que se domine todo tipo de recursos de interpretación. Para hacer una "traducción" de un discurso (verbal) a una película o incluso a una imagen estática hace falta añadir una buena cantidad de nuevos hechos (miradas específicas de las personas, etc.), como observa Eco (2004 [2001]) con razón.

Esta observación puede ser contrarrestada haciendo notar que lo mismo se aplica al pasar de un idioma a otro. Todos los ejemplos clásicos del relativismo lingüístico son relevantes aquí, de Saussure (mouton francés opuesto al mutton y lamb en inglés) y Hjelmslev (francés bois y forêt cubriendo un fenómeno que en muchos otros idiomas corresponde a una sola palabra; véase la discusión en Sonesson 1989) a Whorf y, más recientemente, a Lucy (1998) y 
Slobin (1997: 2000). Para citar un ejemplo sencillo, no hay manera de traducir a muchos otros idiomas un texto finlandés haciendo referencia a su protagonista como hän (finlandés, indiferente para él y ella) sin disponer de información suplementaria, que solo podrá ser accesible al escritor original. Incluso en sueco contemporáneo, donde hen ha sido introducido como pronombre neutro sin especificar el sexo de la persona a que se refiere, no puede haber una verdadera traducción de hän finlandés, siempre que los equivalentes de los pronombres él y ella sigan en uso. ${ }^{4}$ En un nivel más sistemático, los idiomas que obligatoriamente emplean el verbo para describir los movimientos de un lugar a otro (entrar y salir, subir y bajar, como en español) no transmiten la misma información que los idiomas que obligatoriamente emplean el verbo para describir la manera en que uno se mueve (correr, caminar, saltar, etcétera, y muchos otros movimientos que no tienen equivalente en español; cf., para una actualización de la distinción clásica de Talmy, Blomberg 2014), a pesar del hecho de que esta información se puede añadir opcionalmente usando preposiciones, adverbios, etcétera - porque, si esta información no ha sido añadida en el idioma en que es facultativa, solo la persona presente en el lugar original de la acción puede traducir a otro idioma en el que esté-.

No obstante, parece evidente que la discrepancia de información entre, por ejemplo, una imagen y un texto verbal tiene necesariamente que ser inmensamente mayor que entre dos lenguas. Después de todo, los rasgos que diferentes lenguas escogen como relevantes de la realidad experimentada pueden variar enormemente, pero siempre varían en una dimensión, mientras que algunos otros recursos semióticos son multidimensionales. La obra de Shakespeare conocida con el título de Macbeth, que solo conocemos como un trozo de texto escrito, ha dado lugar a numerosas interpretaciones cinematográficas; entre las que destacan la de Orson Welles, Akira Kurosawa y Roman Polanski; también ha dado origen a numerosas representaciones teatrales, la mayoría de las cuales no se han conservado hasta la actualidad, empezando por las de la propia compañía de Shakespeare. Basta considerar al personaje principal llamado Macbeth. La manera de "traducir" en forma visual a este personaje depende de una serie innumerable de opciones en muchas dimensiones diferentes: el tipo de corona, la forma de la cabeza, la forma de la nariz, el contorno de las mejillas, el color de ojos, el tipo de barba,

4 Luego de una breve periodo de uso en la prensa, hen está ahora (como se anunció en la televisión sueca el 18 de agosto de 2014) destinado a aparecer en la próxima edición del Diccionario de la Academia Sueca. 
etc. Por supuesto, en el cine o en una fotografía normalmente no se llegan a seleccionar la mayoría de los parámetros de forma independiente (excepto, de la lista anterior, la corona e incluso, en cierta medida, la barba): hay que seleccionar una porción extendida de propiedades que llevan el nombre de un actor particular. La selección independiente de cada propiedad es, por supuesto, en este caso, una ficción, pero, aun así, algunas opciones pueden tener más importancia que otras en la perspectiva del director de cine al determinar la elección del actor. Por otro lado, en un dibujo, en una película de animación, o incluso en algo que se ve más o menos como una película ordinaria pero que se produce con la ayuda de software $3 \mathrm{D}$, existe la posibilidad de escoger las propiedades una por una. En el caso del cine clásico, la mayor parte de las opciones ya están fijas una vez decidido quién será el actor; aunque todavía haya que decidir desde qué ángulos, a qué distancias, etc., el actor se verá, y esto el texto verbal no tiene que decidirlo.

Otro caso interesante es el de las "bestias fabulosas", tales como grifos, mantícoras, centauros, sirenas y unicornios (cf. Camille 1992; Nigg 1999). Si aceptamos que estos seres nunca han existido, entonces Heródoto, Plinio y otros autores que primero escribieron sobre ellos no los pudieron ver en la vida real, pero posiblemente sí en imágenes. Algunas de estas criaturas, por lo menos, se pueden ver en vasijas griegas, pero estas pinturas probablemente no estaban disponibles para los escritores medievales, que a pesar de ello muy a menudo ilustraron sus escritos con xilografías. Existen muchas maneras en que la idea de un ser combinado de humano, león y escorpión, como el manticora, puede ser "traducido" a imágenes, y muchas variedades fueron también concebidas durante la Edad Media. A partir de entonces, se puede considerar

que existe una tradición verbo-visual combinada de "bestias fabulosas". Tal tradición multisemiótica recuerda la visión de Peirce según la cual los signos se convierten en otros signos que luego se vuelven otros signos más.

A diferencia de la transposición intralingüística, la transposición intersemiótica es sin duda (en el caso normal) un doble acto de comunicación que tiene que tomar en cuenta los casos de remisión y de recepción de ambos actos involucrados.

\section{4. "Traducir" entre el lenguaje y otros recursos semióticos}

Si queremos entender la dificultad de "traducir" de un recurso semiótico a otro, vale la pena echar un vistazo más de cerca a las diferencias entre dos 
de estos recursos semióticos. Gottfried Ephraim Lessing (1766 [1964]) parece haber sido el primero en concebir semióticamente la distinción entre la pintura y la literatura, es decir, en términos de signos visuales y verbales, respectivamente. Según Lessing, las pinturas utilizan signos cuyas expresiones son las formas y colores en el espacio, y tienen una relación icónica (motivada) con respecto a su contenido, mientras que la literatura utiliza sonidos en el tiempo y tiene una relación arbitraria con el contenido. Esto, sin duda, exagera las capacidades y limitaciones de los diferentes recursos semióticos; sin embargo, es cierto que algunos vehículos semióticos se adaptan mejor a determinados fines.

Lessing no respeta la distinción entre cuestiones de hecho y cuestiones normativas: él estipula que el arte debe ser icónico. Pero si dejamos de lado este aspecto, podemos sacar mucho provecho de su trabajo. Algunos semióticos recientes han intentado reformular las distinciones de Lessing en términos del estructuralismo francés (Wellbery 1984), así como en los términos de Peirce (Bayer 1975). Ambos procedimientos son sin duda muy esclarecedores, pero, curiosamente, ninguno de estos estudiosos ha permitido avanzar en el proceso de investigación. Una vez que se considera la diferencia de perspectiva, no hay, en mi opinión, ninguna razón para no entrar en diálogo, sin duda unilateral, con Lessing. En algunos de mis escritos anteriores, he tratado de iniciar ese diálogo, pero aquí solo puedo ofrecer un resumen de mis conclusiones (cf. Sonesson 1988, 1996).

Según Lessing, el lenguaje verbal puede abordar cualquier tema: lo que Hjelmslev llama un "lenguaje de llave maestra". Las imágenes, por otro lado, solo pueden rendir directamente - la parte más grande del dominio detodo lo visible, o todo lo que tenga homólogos visibles. Si hemos de creer en Lessing y muchos pensadores posteriores, entre ellos en Nelson Goodman (1968), las imágenes no solo tienen la capacidad de describir la totalidad del espacio, sino que no pueden evitar hacerlo: solo pueden mostrar "entidades totalmente determinadas". Esto no es cierto en lo absoluto: como he mostrado, al contrario de la tesis de Goodman, la "densidad" de las imágenes es solo relativa, y todo tipo de abstracción se encuentra en ellas (cf. Sonesson 1989: 226 y ss. y 324 y ss.; 1995). Esto se aplica al plano de la expresión, en el caso de las imágenes más o menos esquemáticas, tales como señales de tráfico y logotipos, pero también se aplica al plano de contenido de las imágenes cuyos planos de expresión son completamente "densos". En otras palabras, incluso las imágenes muy "naturalistas" (pinturas e incluso fotografías) pueden no 
llevar más significado que el de presentar "una guardia" (como en el ejemplo de Gombrich que critica Sonesson 1989), "un soldado", "una mujer joven”, o incluso "un ser humano". Por lo tanto, para fines prácticos, muchas imágenes no son signos de individuos, sino de papeles abstractos en situaciones más o menos genéricas.

Al comentar los estudios de Lessing, Bayer (1975) observa que los cuerpos (los objetos) son portadores de acciones, es decir, que las acciones presuponen la existencia de cuerpos que corresponden a acciones. Las acciones, sin embargo, son continuas, pero solo pueden ser representadas icónicamente en forma de estados discretos. El esquema de distribución de las imágenes no permite la sucesión, con excepción de las acciones representadas indirectamente por medio de los cuerpos y las acciones colectivas donde varias personas actúan juntas.

\begin{tabular}{|c|c|}
\hline $\begin{array}{l}\text { Lo que las imágenes } \\
\text { pueden representar }\end{array}$ & $\begin{array}{l}\text { Lo que el lenguaje } \\
\text { puede representar }\end{array}$ \\
\hline $\begin{array}{l}\text { Nada más entidades relativamente } \\
\text { determinadas }\end{array}$ & $\begin{array}{l}\text { Todos los objetos, pero solamente repre- } \\
\text { sentados en forma de un número limitado } \\
\text { de propiedades abstraídas de la totalidad } \\
\text { del mundo de la vida }\end{array}$ \\
\hline $\begin{array}{l}\text { “Cuerpos” (continuidades espaciales) } \\
\text { representados directamente }\end{array}$ & 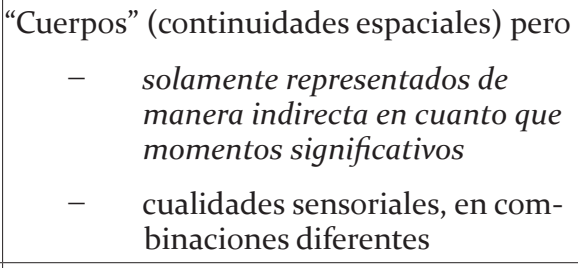 \\
\hline $\begin{array}{l}\text { “Eventos” (continuidades temporales) } \\
\text { Representados directamente por } \\
\text { huellas dejadas en los “cuerpos” (con- } \\
\text { tinuidades espaciales) } \\
\qquad \begin{array}{l}\text { o representados directamen- } \\
\text { te en el teatro y en el cine }\end{array}\end{array}$ & \begin{tabular}{|c} 
“Eventos" (continuidades temporales) \\
$-\quad$ con pocas excepciones también \\
limitados a momentos significa- \\
tivos y cualidades sensoriales
\end{tabular} \\
\hline $\begin{array}{l}\text { Sin estructura temática obvia - con } \\
\text { excepción del cine y de los comics }\end{array}$ & Estructuración temática \\
\hline $\begin{array}{l}\text { Estructuras narrativas virtuales y } \\
\text { abiertas (con excepción del cine y, } \\
\text { en cierta medida, los comics) }\end{array}$ & Estructuras narrativas determinadas \\
\hline
\end{tabular}

CUADRO 2. Las restricciones en la semiosis verbal y visual, como sugiere Lessing 1766 [1964] (en letras redondas) y revisadas por Sonesson 1988 y 1996 (en letras cursivas). 
La dificultad que plantea la narratividad en las imágenes, como Bayer interpreta a Lessing, es que la imagen no puede referirse a cosas abstractas, en el sentido de que tiene que mostrar todo el conjunto de propiedades de una cosa a la vez: Homero puede mostrar a los dioses bebiendo y discutiendo al mismo tiempo, pero las imágenes son incapaces de transmitir toda esta información. A mi parecer, no es la cantidad de información lo crucial (la imagen puede fácilmente llevar más), sino la posibilidad de organizarla: el lenguaje verbal tiene dispositivos específicos para indicar la importancia relativa, la novedad, el tema, etc., pero no parece haber nada comparable en las imágenes: sin duda hay algunos géneros de imágenes donde la convención nos obliga a poner las cosas importantes en el centro (más estrictamente en la pintura icónica rusa), de aumentar su tamaño (como en gran parte de pintura europea medieval), a usar otros colores para dar énfasis (en su mayoría en los diagramas), etc., pero estos no son dispositivos generales (cf. Sonesson 1995). El problema no consiste en mostrar a los dioses bebiendo y discutiendo al mismo tiempo: el problema es marcar una de estas actividades en primer plano y la otra en el fondo (a pesar de la metáfora visual). En la imagen, el espacio de representación es, al mismo tiempo, la representación del espacio de la percepción humana ordinaria, lo que dificulta cualquier tipo de organización por otros sistemas. Algunas modificaciones a este principio fueron presentadas por el cubismo, por Matisse, por algunas formas de collages e imágenes sintéticas, y también por algunos sistemas visuales de información como logotipos, símbolos de Bliss, señales de tráfico, etcétera.

Según Lessing, utilizando la terminología empleada por Bayer, las imágenes pueden representar a los "cuerpos" (la continuidad espacial) directamente, es decir, como entidades relativamente determinadas, pero representan a los "eventos" (la continuidad temporal) solo indirectamente por medio de las huellas dejadas en los cuerpos (la continuidad espacial); es decir, en términos de momentos significativos. En la misma terminología, se puede decir que el lenguaje puede representar todas las unidades, los "eventos" (la continuidad temporal) directamente, y los "cuerpos" (la continuidad espacial) indirectamente, pero solo en la forma de un número limitado de propiedades abstraídas de las totalidades existentes en el mundo de la vida, es decir, como cualidades sensoriales en diferentes combinaciones. Si es así, la lengua verbal, lejos de ser un "lenguaje de llave maestra", es defectuosa en su forma 
de representar la continuidad espacial, al igual que las imágenes lo son en el caso de la representación de la continuidad temporal.

No obstante, hay un error grave en el conjunto de razonamiento de Lessing, no detectado por Bayer o Wellbery: desde luego, no es cierto que el lenguaje es particularmente apto para representar continuidades temporales de manera icónica (cf. Sonesson 1995). El lenguaje se compone de continuidades temporales (al menos en su forma hablada), pero la continuidad temporal que el lenguaje se esfuerza en transmitirnos la mayor parte del tiempo no es una continuidad lingüística. El lenguaje no ofrece más recursos que las imágenes para representar la continuidad temporal no lingüística. A pesar de que el lenguaje es básicamente arbitrario, contiene algunos términos icónicos, por ejemplo, en las palabras onomatopéyicas, pero lo icónico de ellas rara vez es su temporalidad. La sintaxis puede, por supuesto, ser utilizada para introducir alguna secuencia icónica: por ejemplo, "Veni, vidi, vinci", si asumimos que los tres actos han tenido lugar en ese orden, pero esta iconicidad no se extiende al interior de cada palabra. ${ }^{5}$ Tal vez el mejor ejemplo de iconicidad temporal a gran escala sería el comentarista de radio que describe un evento deportivo en el momento en que se desarrolla. Sin embargo, en general, el gesto tiene más capacidad de representar continuidades temporales empleando relaciones de iconicidad.

Incluso si las imágenes no pueden realmente representar entidades totalmente determinadas, sin duda se acercan más a esta meta, incluido el caso de continuidades temporales como en el lenguaje. La imperfección del lenguaje verbal, que es al mismo tiempo su gran fuerza, consiste en que no puede representar nada, sea continuidad temporal o espacial, o lo que sea, sino como cualidades sensoriales, es decir, en forma de un conjunto limitado de propiedades abstraídas de las totalidades de las que se compone el mundo de nuestra experiencia. Así como la noción misma de "momentos significativos" implica representar solo algunas — pero idealmente las más importantes- de las propiedades de continuidades temporales, las “cualidades sensoriales", según entiendo yo el término, son el resultado de la extracción de, idealmente, las propiedades más importantes de las continuidades espaciales. Contraria-

5 Christensen, Fusaroli y Tylén 2016 han demostrado que hay una diferencia icónica entre el orden en que se comunican los eventos de construcción (por ejemplo, hacer un pastel) y los eventos de manipulación (por ejemplo, dejar caer un pastel) si se usan gestos, pero los lenguajes en general tienen un orden prescrito en que se pone el sujeto, el objeto, y el verbo, que no permite hacer esta diferencia. 
mente a Lessing, Bayer y Wellbery, sostengo que las imágenes están limitadas en cuanto al número de cualidades sensoriales que pueden transmitir, pero no tan limitadas como el lenguaje. Una imagen puede seguramente decir más que mil palabras, y mucho más allá de eso, pero nunca dirá tanto como la realidad perceptiva. En cuanto a los momentos significativos, el lenguaje solo puede ir más allá de ellos (y raras veces de una forma icónica) añadiendo más signos (que por lo general significa añadir frases o párrafos). Por eso la "traducción" de un discurso verbal a una imagen es una tarea más difícil de realizar que al revés: una inmensa cantidad de propiedades simplemente no están disponibles. Pero la tarea contraria también es desalentadora, por otra razón: cuando uno "traduce" una imagen - y una percepción - en forma de lenguaje, tiene que realizar una serie de decisiones sobre la forma de organizar el discurso en términos de jerarquías temáticas, y de nuevo la información requerida por lo general no está disponible para el traductor.

Jakobson parece dar por sentado que en toda "traducción" entre diferentes dominios semióticos uno de estos tiene que ser el lenguaje. Normalmente este puede ser el caso, no solo porque el lenguaje es tan fundamental para los seres humanos como se supone comúnmente, sino porque el lenguaje y lo visual lo son. Queda mucho por decir, sin duda, si tuviéramos suficiente tiempo y espacio, sobre la transposición entre los diferentes dominios visuales, entre las imágenes y los gestos, entre las imágenes estáticas y las películas, y así sucesivamente.

\section{Conclusión:}

\section{La traducción como un tipo específico de transposición}

Como doble acto de comunicación, la traducción no se puede entender solamente como dos actos de comunicación uno seguido del otro, sino, como lo hemos mostrado, el contenido de los dos actos de comunicación debería ser, en el sentido calificado del término, idéntico a lo largo de los actos, lo cual, por diferentes razones, es imposible en la transposición intralingüística y la transposición intersemiótica. Sin embargo, el problema es: ¿qué se entiende por la noción de un sentido calificado de la identidad del contenido? Al final, solo la ética puede dar cuenta de la diferencia. Como todo el mundo sabe, hay un refrán italiano que dice: "traduttore, traditore" [traductor, traidor]. Dada la diferencia de medios (que aumenta enormemente con la transposición intersemiótica), el traductor/transpositor nunca podrá representar to- 
dos los detalles del mensaje original. Pero la instancia reguladora, o telos, de este doble acto de comunicación consiste claramente en transmitir el mismo significado, dentro de los límites de lo posible. Sea cual sea su instancia reguladora, este telos no es ciertamente el objetivo de la publicidad, ni, como hemos sugerido anteriormente, de transposiciones culturales. No obstante, esto no es normalmente el telos de una transposición intralingüística cualquiera (excepto en el caso de la adaptación al receptor), y no es el telos necesariamente en el caso de la transposición intersemiótica. No es obvio que Welles, Kurosawa y Polanski hayan hecho sus películas con la meta de representar las intenciones que Shakespeare tenía al escribir Macbeth. A diferencia del caso de la publicidad, donde el significado es opuesto; y la transposición cultural, donde se trata de una deformación o un camuflaje; la transposición intersemiótica sin duda tiene en vista crear una especie de equivalencia, aunque posiblemente de manera bastante difusa. En cuanto a la cadena peirceana de interpretantes, en la tradición, e incluso en el rumor, su función parece más bien ser la de producir una identidad que incluya una diferencia. Inicialmente nos propusimos encontrar la definición de la traducción, pero, al fin y al cabo, descubrimos toda una gama de diferentes actos de creación de significados.

\section{Referencias bibliográficas}

BAYER, Udo. (1975). Lessings Zeichenbegriffe und Zeichenprozesse im 'Laokoon' und ihre Analyse nach der modernen Semiotik. Tesis, Stuttgart.

BLOMBERG, Johan (2014). Motion in language and experience: actual and non-actual motion in Swedish, French and Thai. Tesis, Lund: Lunds Universitet.

CAMille, Michael (1992). Image on the edge: the margins of medieval art. Cambridge, Mass.: Harvard University Press.

Christensen, Peer, Riccardo Fusaroli y Kristian Tylén (2016). "Environmental Constraints Shaping Constituent Order in Emerging Communication Systems : Structural Iconicity, Interactive Alignment and Conventionalization”, en Cognition, 146, pp. 67-80.

EcO, Umberto (2004 [2001]). Experiences in translation. Toronto: University of Toronto Press

GoOdman, Nelson (1968). Languages of art: an approach to a theory of symbols. Indianapolis: Bobbs-Merrill Comp.

Jakobson, Roman (1959). “On Linguistic Aspects of Translation”, en On Translation. Brower Reuben (ed.), 232-239. Cambridge, Mass.: Harvard University Press. 
Lessing, Gottfried Ephraim (1766 [1964]). Laokoon - oder Über die Grenzen der Malerei und Poesie. Berlín: Philipp Reclam Jun., Stuttgart.

Lucy, John A. (1998). "Space in Language and Thought: Commentary and Discussion", en Ethos, 26, 1: 105-111.

NIGG, Joe (ed.) (1999). The book offabulous beasts: a treasury of writings from ancient times to the present. New York: Oxford University Press.

Prieto, Luis J. (1966). Messages et signaux. París: Presses universitaires de France.

Slobin, Dan I. (1997). "Mind, code and text", en Essays on language function and language type. J. Haiman, Bybee, J. y S. Thompson, (ed.), Philadelphia: Benjamins: 437-467.

Slobin, Dan I. (200o). "Verbalized Events”, en Evidence for linguistic relativity. S. Niemeier y R. Dirven (ed.), Amsterdam: Benjamins: 107-137.

SonESSON, Göran (1988). Methods and Models in pictorial semiotics. Report from the Semiotics Project, Lund.

Sonesson, Göran (1989). Pictorial concepts. Lund: Lund University Press.

SonESSON, Göran (1995). "On pictorality. The impact of the perceptual model in the development of visual semiotics”, en The semiotic web 1992/93: Advances in visual semiotics, Th. Sebeok y J. Umiker-Sebeok (ed.), Berlin y New York, Mouton de Gruyter: 67-108.

SonESSON, Göran (1996). "The quadrature of the hermeneutic circle", en LSP and theory of translation. Acts of the XVI Vakki symposion, Text and Image, Vöjri, February 10-12, 1996. Vaasa: 9-33.

SonEsson, Göran (2014b). "Translation and Other Acts of Meaning. In Between Cognitive Semiotics and Semiotics of Culture", en Cognitive Semiotics, 7, 2, 2014: 249280.

Wellbery, David E. (1984). Lessing's Laocoon. Semiotics and aesthetics in the Age of Reason. Cambridge, Cambridge University Press.

\section{Göran Sonesson}

Es profesor de semiótica y director de la División de Semiótica Cognoscitiva de la Universidad de Lund. Obtuvo su doctorado en lingüística general en la Universidad de Lund en 1978 y, en el mismo año, en semiótica en la École des Hautes Études en Sciences Sociales. Sus tesis doctorales tratan, respectivamente, de colocar el lenguaje y el gesto dentro de un marco semiótico más amplio basándose en la fenomenología y la psicología de la percepción. La mayor parte de su investigación se ha centrado en el estudio semiótico de las imágenes, que ha investigado desde un punto de vista teórico, enfocado desde una perspectiva fenomenológica, y, en décadas más recientes empíricamente, de forma experimental. En su libro Pictorial concepts (1989) presentó la única refutación completa existente de la crítica de la iconicidad, formulada por Umberto Eco, 
Arthur Bierman y Nelson Goodman, al tiempo que revisó críticamente el trabajo sobre las capas plásticas e icónicas de las imágenes delineadas en las teorías de la escuela Greimas y del grupo de retórica semiótica de Lieja. Su otra especialidad, desde la última década del siglo $\mathrm{xx}$, ha sido una reinterpretación de la semiótica de la cultura tal como la entiende la escuela de Tartú, conectándola con la distinción fenomenológica entre Mundo casero y Mundo ajeno. En los últimos años, ha estado dedicado a la teoría de la evolución cultural, criticando la sociobiología, y presentándola como una extensión histórica de la semiótica cultural. También ha investigado los fundamentos epistemológicos y metodológicos de la semiótica cognoscitiva, que tiene como objetivo reunir las ventajas de la semiótica y de la ciencia cognoscitiva, uniendo críticamente sus conceptos y métodos. Ha escrito numerosos artículos en reconocidas revistas semióticas y antologías, y también ha publicado artículos en revistas psicológicas y sociológicas. Fue miembro fundador de la Asociación Internacional de Semiótica Visual y de la Asociación Internacional de Semiótica Cognoscitiva. 